\title{
Achieving monospermy or preventing polyspermy?
}

This article was published in the following Dove Press journal:

Research and Reports in Biology

13 June 2016

Number of times this article has been viewed

\section{Brian Dale}

Centre for Assisted Fertilization, Naples, Italy
Correspondence: Brian Dale

Centre for Assisted Fertilization, Via

Tasso 480, Naples, 80123, Italy

$\mathrm{Tel}+39813316173618$

Email brian.dale@virgilio.it
Abstract: Images of sea urchin oocytes with hundreds of spermatozoa attached to their surface have fascinated scientists for over a century and led to the idea that oocytes have evolved mechanisms to allow the penetration of one spermatozoon while repelling supernumerary spermatozoa. Popular texts have extrapolated this concept, to the mammals and amphibians, and in many cases to include all the Phyla. Here, it is argued that laboratory experiments, using sea urchin oocytes deprived of their extracellular coats and inseminated at high densities, are artifactual and that the experiments leading to the idea of a fast block to polyspermy are flawed. Under natural conditions, the number of spermatozoa at the site of fertilization is extremely low, compared with the numbers generated. The sperm:oocyte ratio is regulated first by dilution in externally fertilizing species and the female reproductive tract in those with internal fertilization, followed by a bottleneck created by the oocytes extracellular coats. In order to progress to the oocyte plasma membrane, the fertilizing spermatozoon must encounter and respond to a correct sequence of signals from the oocytes extracellular coats. Those that do not, are halted in their progression by defective signaling and fall to the wayside. Final success and entry is finely tuned by the spermatozoon anchoring to an actin-rich predetermined site on the plasma membrane. In this review, the variation in the form, function, and number of gametes produced across the animal kingdom and the many ways in which sperm-oocyte interactions are regulated to reduce numbers are discussed. Since in nature, final sperm:oocyte ratios approach unity it would appear that selective pressures have favored the achievement of monospermy, rather than the evolution of polyspermy preventing mechanisms.

Keywords: monospermy, natural conditions, polyspermy, laboratory artifacts, sperm:oocyte ratios.

\section{What happens in the laboratory? Activation events that have been adopted as polyspermy preventing mechanisms Historical}

Ernst E Just in the 1920s was particularly interested in the cortex of oocytes and its role in controlling the behavior and destiny of the cell. He forwarded the idea that a wave of negativity crossed the surface of the sea urchin oocyte rendering its surface unreactive to other spermatozoa, and really set the scene for the hypothesis of the "fast electrical block to polyspermy."

"Any worker possessing only mediocre powers of observation, therefore, should be able to prove to his own satisfaction that eggs, of these three forms at least (referring to three 
species of Sea urchin), separate membranes, beginning at the point of sperm entry."

Quote from Ernst E Just. ${ }^{1}$

"Before the actual elevation of the fertilization membrane, some cortical change beginning at the point of sperm entry sweeps over the egg, immunizing it to other sperm." In 1939, Just, in his landmark book, ${ }^{2}$ suggested this change may be attributable to nerve conduction, "because among animal cells it is the most highly excitable and the most rapidly conducting."

However, Just was also aware that mishandling gametes in preparation for an experiment led to artifacts.

\section{The sea urchin model}

Due to their abundance and ease to use, marine invertebrate oocytes have been used for centuries in the laboratory, with the sea urchin, being favored by many renowned scientists such as Hertwig, Boveri, and Herbst. ${ }^{3}$ In contrast to the situation in most animals, sea urchin oocytes have completed meiosis when they are ovulated and are often called eggs. In this review, I will use the term oocyte, in keeping with the other animals mentioned, and use the term germinal vesicle oocyte $(\mathrm{GV})$ to indicate an immature sea urchin oocyte. Images of sea urchin oocytes with thousands of spermatozoa attached to their surface invoked the general concept that one successful spermatozoon entered, inducing changes in oocyte physiology, which inhibited progression of the other spermatozoa. This change was suggested to be composed of a slow permanent block, the cortical reaction, ${ }^{4}$ and a faster partial block ${ }^{5}$ and in the 1970 s, it was proposed that the fast block was electrical. ${ }^{6}$

Sea urchins are a member of the echinoderm family and are found globally. Animals are collected by divers often without taking into account their breeding patterns or sexual maturity. Gametes are obtained, either by injecting a concentrated salt solution into their body cavity or by manual dissection. The oocytes are surrounded by a jelly layer, which is often indiscriminately removed (by acid treatment) and these large cells are often attached electrostatically to slides to flatten them out, both for imaging or electrophysiological recording. Meiotic and cytoplasmic maturity in sea urchin oocytes are often asynchronous ${ }^{7}$ and they undergo aging in vitro. ${ }^{8,9}$

Thus, in using marine oocytes, one has to be careful and take into account that an experiment has not already been done in the preparation of the material to suit the experimenter.

If the condition of the eggs is not taken into account, the results obtained by the use of subnormal eggs in experiments may be due wholly or in part to the poor physiological condition of the eggs. Thus, the failure of sea urchin eggs that are freed of their jelly, fully to separate their vitelline membrane after fertilization, as they normally do, does not mean that the experimental removal of jelly renders membrane separation impossible but only that the eggs are in a bad condition brought about by injurious action of the agent employed to remove the jelly.

The basis and the control of any experiment is the perfectly normal egg; the worker must know therefore what is a good egg.

Descriptive embryology built upon laboratory observations stands only if one can assume that the stages observed represent faithful reproductions of those occurring in nature [...].

Quote from Ernst E Just. ${ }^{2}$

\section{The cortical reaction}

At activation, the oocyte changes its role from a quiescent cell programmed to interact with its male counterpart, to a dynamic zygote that must be kick-started to progress through early development. The early embryo must be protected and isolated from its environment. Protection is afforded by the cortical reaction. Just below the surface of the sea urchin oocyte lies 20,000 granules, each measuring $\sim 1$ micron in diameter containing a cocktail of enzymes and macromolecules, including proteins, hyaline, a serine protease, a peroxidase, and several sulfated mucopolysaccharides. Cortical granules are derived from the Golgi apparatus and migrate to the periphery during maturation. They release their contents into the perivitelline space, following interaction with the fertilizing spermatozoon, by fusing to the oocyte plasma membrane. Fusion starts at the site of sperm entry and then traverses the oocyte in a wave to the antipode taking $\sim 30$ seconds to complete. Following the cortical reaction, a tightly adhering protective layer around the oocyte called the hyaline layer is formed, ${ }^{10-12}$ while the peroxidase hardens the elevated fertilization membrane by cross-linking the tyrosine residues of the vitelline coat aided by hydrogen peroxide. This leads to a net increase in the total surface area of the plasma membrane, which can be observed as a transient increase in length of microvilli, and presumably changes the permeability and exchange properties of the oocyte with the environment. ${ }^{13-16}$ Therefore, it appears that the cortical reaction has evolved to change the receptive outer investment of the oocyte into a hardened protective layer to protect the developing embryo in the early stages of embryogenesis and to provide a microclimate for the early division cycles and morphometric movements. 


\section{Kinetic experiments of Lord Rothschild}

Rothschild and Swann in the 1940-1950s studied spermoocyte interaction in sea urchins at various concentrations and conditions and came up with the idea that the fertilizing spermatozoon induced a fast, yet partial, change in the oocyte surface that preceded the cortical reaction and that reduced sperm receptivity by $1 / 20$ th.

"It has of course been known since the 19th century that the surface of the sea urchin egg changes at fertilization, and the method of observing this change, whether with polarized light, dark ground illumination, or ordinary light."17

Observing sea urchin oocytes, under dark field illumination, the authors noted a change in the scattering of light properties that covered the oocyte cortex in $\sim 20$ seconds at $18^{\circ} \mathrm{C}$.

"At the site of spermatozoon entry, there is a localized and transient decrease in light scattering, the elevation of a fertilization cone and it is here that the fertilization membrane starts to elevate."

Rothschild then took the assumption that a suspension of spermatozoa was analogous to an assembly of gas molecules, and calculated the number of sperm-oocyte collisions at $10^{5} /$ $\mathrm{mL}$ to be 1.6 , at $10^{6} / \mathrm{mL}$ to be 16 , and at $10^{7} / \mathrm{mL}$ to be 160 , assuming the translator speed of sperm to be 190 microns/s.

Using immature oocytes (the GV stage), Rothschild and Swann ${ }^{17}$ demonstrated that from an expected 4,500 collisions at a sperm density of $10^{7} / \mathrm{mL}$, in a 5 -minute period, $<100$ actually entered the oocyte. The authors concluded ${ }^{17}$ "only a fraction of the spermatozoa which collide with the egg surface are able to initiate activation" and

"attachment of the spermatozoon to an egg is not followed by fertilization unless there exists a particular orientation on a molecular scale, between the egg and sperm surfaces, and provided there has been no previous interaction between spermatozoa and Gynogamone II" (an agglutinating substance released from eggs).

In later experiments, Rothschild and Swann ${ }^{18,19}$ mixed oocytes and sperm at known densities for varying periods of time and, by treating the fertilization reaction as a first-order chemical reaction, found that the fraction of monospermic oocytes increased in time according to the relationship

$$
\mathrm{M}(\mathrm{t})=1-\mathrm{e}^{-\alpha \mathrm{t}} \text { below sperm densities of } 3 \times 10^{6} / \mathrm{mL} .
$$

The relationship is similar for polyspermic oocytes at densities between $7 \times 10^{7} / \mathrm{mL}$ and $3 \times 10^{8} / \mathrm{mL}$ giving a rate of appearance of polyspermic oocytes as $\alpha^{1}$.
They argued that since $\alpha^{1}$ (the refertilization rate) was found to be much less than $\alpha$ (the monospermic rate), a rapidly acting partial block reduced the probability of successful reactions after the first had occurred. In order to perform these calculations of refertilization rates (to fix a $T=0$ ), the authors used a totally unnatural sperm concentration of $10^{8} / \mathrm{mL}$, which is slightly less than that found in the testis before dilution. Rothschild and Swann ${ }^{18,19}$ point out the drawbacks of their own experiments: Since $\alpha^{1}$ is the rate of increase of polyspermic eggs, it is perforce an underestimate of the successful collision rate because it does not take into account the actual number of sperm per polyspermic egg. In addition, the nonlinear dependence of $\alpha$ on $n$ may be due to sperm-sperm interactions at higher densities, while we have not taken into account chemotaxis from egg exuded components, the presence of the jelly or the declining fertilizing capacity of spermatozoa in time.

\section{The kinetic experiments are flawed}

Although an exercise to be studied by all students of biology, the Rothschild hypothesis has fundamental flaws: first, fertilization is not a first-order chemical reaction and spermatozoa are not analogous to gas molecules. Second, it does not consider the possibility that there are a limited number of sperm entry sites on the oocyte surface. Lastly, it assumes that all spermatozoa are equal in their capacity to penetrate the cell. This is incorrect. Only competent spermatozoa that encounter and respond to the correct sequence of triggering events as they progress through the oocyte investments are successful.

\section{Experiments that led to the proposal for a fast electrical block to polyspermy}

In the 1970s, with the advent of more sophisticated electrophysiological recording techniques, the intuitive Rothschild hypothesis on a fast polyspermy block in sea urchin oocytes was translated into a physiological parameter - transmembrane voltage!

$\mathrm{Jaffe}^{6}$ identified two types of electrical response at fertilization. From a total of 21 current clamp recordings, eight oocytes gave rise to a positive fertilization potential (ie, that overshot $0 \mathrm{mV}$ ), while 13 oocytes generated a fertilization potential less positive than $-10 \mathrm{mV}$. Since the former oocytes were all monospermic, while the latter were either monospermic or polyspermic, the author came to the conclusion: "These results suggest that the entry of extra sperm is prevented by the more positive-going activation potential." ${ }^{6}$ The authors also demonstrated that unfertilized oocytes artificially held at a positive potential by the injection 
of large amounts of current could not be fertilized. This intuitively attractive initial report was soon contrasted by more substantial studies using the correct electrophysiological configuration of holding the transmembrane potential at various voltages, the voltage clamp configuration.

\section{Electrophysiological data suggesting a fast electrical block is artifactual}

Shen and Steinhard ${ }^{20}$ demonstrated that while positive voltages blocked the entry of all the spermatozoa attached to the surface of the oocyte, a negative repolarization permitted the entry of only one spermatozoon. The authors concluded ${ }^{20}$

"we were somewhat surprised to observe a low rate of polyspermy after the application of a window of negativity. Despite the presence of numerous sperm, all presumably blocked at the same point, nearly all the fertilizations were monospermic."

Using a fluorescent dye to indicate cell-cell fusion, Hinkley et $\mathrm{al}^{21}$ showed that in sea urchin oocytes voltage clamped at $-20 \mathrm{mV}$, only one spermatozoon fused with the oocyte. Meanwhile, Lynn et al, ${ }^{22}$ using clamp voltages of -20 to +17 $\mathrm{mV}$, showed that normal monospermic entry was associated with a typical biphasic fertilization current and quoted "As many as 5-25 sperm may attach before a successful encounter occurs that results in an electrophysiological response." These experiments show that the fertilizing spermatozoon is intrinsically different to supernumerary spermatozoa or that it is located at a preferential entry site, irrespective of the membrane voltage.

\section{Holding the oocytes transmembrane voltage at unnatural levels is artifactual}

In order to measure directly the ion currents across a biological membrane, it is necessary to voltage clamp the membrane, either by the whole cell clamp technique or by using two intracellular electrodes, one to measure the current, the other to inject current to move the transmembrane voltage to a particular value. Voltage clamp was traditionally designed for nerve and muscle cells or in any case cells that are, at most, exposed to variations in voltage or to the application of drugs.

A sea urchin oocyte is nearly 1 million times the volume of a spermatozoon. As it penetrates the oocyte investments, the spermatozoon encounters a sequence of molecular triggers that leads to its physiological competence. ${ }^{23}$ Clamping the oocyte at a voltage extraneous to its natural resting potential requires injecting large amounts of current into the oocyte, which will cause a molecular reorganization of the oocyte plasma membrane (frying), interfering with the normal processes of sperm-oocyte interaction. Clamping around the natural resting potential, or at least in a range where little current is required to hold the membrane steady, that is, -20 to $+15 \mathrm{mV}$, permits sperm entry.

\section{Monitoring the kinetics of sperm-oocyte interaction by electrical recordings}

Since sea urchin oocytes are large and transparent and are easy to penetrate with intracellular microelectrodes, changes in voltage over time have been used to follow fertilization events. Many spermatozoa attach to the jelly-free oocyte, before one, the fertilizing spermatozoon, distinguishes itself by gyrating around its point of attachment. ${ }^{24}$ Approximately 3 seconds later, a small electrical step depolarization occurs, with no change in the morphology of the oocyte surface or sperm behavior, until a further 9 seconds later when a larger bell-shaped depolarization starts. ${ }^{24}$ The successful spermatozoon then stiffens, stops gyrating, and the cortical reaction is initiated at this point. A protuberance of the oocyte cortex (the fertilization cone) is formed and the sperm head slowly disappears into this cone, while the cortical reaction spreads across the oocyte to the antipode. The cortical reaction leads to the elevation of the fertilization membrane and is completed during the repolarizing phase of the fertilization potential. ${ }^{24}$ The time period between the attachment of the successful spermatozoon and the initiation of the cortical reaction is known to be $\sim 13$ seconds at room temperature, is temperature-dependent, ${ }^{25}$ and has been called the latent period. ${ }^{12}$ In the latent period, which correlates with the time delay between the two electrical events, that is, the step depolarization and the start of the slower fertilization potential, a microfilament-dependent process appears to occur. ${ }^{26}$ If a germinal vesicle $(\mathrm{GV})$ oocyte is impaled with an intracellular microelectrode and inseminated, the events are different to mature oocytes. GV oocytes do not undergo the cortical reaction, as their cortical granules have not yet migrated to the cell surface, and they are naturally polyspermic. Using equivalent sperm concentrations, the step depolarizations occur within 5 seconds of insemination; however, the fertilizing spermatozoa gyrate for 30-60 seconds before stiffening and being engulfed by the fertilization cones. Unsuccessful spermatozoa, that is, those that do not enter the oocyte, maybe identified by one of two behaviors. First, some spermatozoa attach to the surface, but do not generate either electrical step depolarizations or fertilization cones, and these continue gyrating around their point of attachment for several minutes until their energy 
resources are depleted and they fall limp to the oocyte surface. A second category of unsuccessful spermatozoa generate step depolarizations that subsequently reverse after $\sim 50$ seconds; however, these spermatozoa also do not induce fertilization cone formation, nor enter the oocyte. Using transmission electron microscopy, it was shown that $95 \%$ of attached spermatozoa at 20 seconds insemination are not acrosome reacted..$^{27,28}$

Using the voltage clamp configuration, Longo et $\mathrm{al}^{29}$ fixed sea urchin oocytes at various times after insemination and showed that the first electrical event was detected 2 seconds after attachment, with gamete fusion occurring at 7 seconds and cortical exocytosis starting at 9 seconds. The fertilization potential was detected at 13 seconds. Sea urchin oocytes can be loaded with a fluorescent dye and cytoplasmic continuity between sperm and oocyte can be determined when the dye flows into the spermatozoon. ${ }^{21}$ By inseminating voltage clamped $(-20 \mathrm{mV})$ dye-loaded eggs, Hinkley et $\mathrm{al}^{21}$ inferred that cell-cell continuity occurred at $4-8$ seconds after the initial electrical event.

\section{What happens in nature?}

\section{Form, function, and numbers of gametes}

We have argued previously that laboratory experiments with large numbers of spermatozoa and oocytes deprived of their extracellular layers are artifactual and have led to the idea of the oocyte possessing active mechanisms to allow the entry of one spermatozoon, while rejecting supernumerary spermatozoa. The main culprit has been the sea urchin, however, more recently this hypothesis has been extrapolated to mammals, another group that lends itself to laboratory conditions. Furthermore, popular texts have misguided readers into believing that this situation is common across the animal kingdom. This is far from the truth. Gametes vary enormously in form, function, and numbers produced and accordingly there are many ways in which sperm-oocyte interactions are regulated.

\section{Sperm entry sites}

In insects, squid, and some teleosts, the oocytes lack cortical granules and the extracellular coat is impenetrable, called the chorion. It is worth noting in these species that the spermatozoa lack an acrosome. ${ }^{30}$ In these species, the spermatozoa enter the oocyte through a preformed entry site, the micropyle, ${ }^{31}$ where, in fish at least, a sperm attractant, a glycol-protein, has been identified responsible for guiding the spermatozoa to the micropyle. ${ }^{32}$ In the anuran, Discoglossus pictus, oocytes are highly polarized with the animal pole marking the position of the meiotic plate and organelles distributed in a gradient toward the vegetal pole. Here, the spermatozoa may only enter through a restricted depression at the animal pole, called the dimple, where the fine structural organization is different to the rest of the oocyte surface. ${ }^{33}$ In tunicates, the spermatozoon enters the oocyte at a preferential site at the vegetal pole. Polarized sperm entry coincides with polarized oocyte activation events. The first event being the release of calcium from intracellular stores, which traverses the oocyte from the point of sperm entry to the antipode in a wave. ${ }^{34}$ For example, in jellyfish and the anuran Xenopus laevis, where the sperm enters the animal pole of the oocyte, the calcium wave starts at the animal pole and traverses the oocyte to the antipode. ${ }^{35,36}$ while in ascidian and nemertean oocytes, the wave initiates at the vegetal pole, the site of sperm entry. ${ }^{37,38}$ In teleosts, where the spermatozoa are forced to enter at the animal pole through the micropyle, the calcium wave starts at the animal pole. ${ }^{39-41}$ Since in mammals and echinoderms, the calcium wave is also initiated at the point of sperm entry, ${ }^{42-45}$ more work is necessary to determine whether in these groups there are also preferential sperm entry sites.

\section{Naturally polyspermic animals}

In other animals, it is normal for more than one spermatozoon to enter the oocyte cytoplasm; however, only one sperm nucleus interacts with the maternal nucleus to form the zygote nucleus, while the others degenerate. Physiologically polyspermic animals include ctenophores, many insects, elasmobranchs, some amphibians, reptiles, and birds., ,5,30,46 $^{4}$ The most classical studies include those on the urodeles by Fankhauser ${ }^{47-49}$ and those in birds by Harper. ${ }^{50}$ In birds, hundreds of millions of sperms are inseminated, but only a few hundred reach the ovum, ${ }^{51}$ the vast majority are ejected by the female tract early after copulation. Recently, it has been shown in the zebra finch and domestic fowl that the female tract regulates the number of sperm reaching the site of fertilization and it has been suggested that although one or few spermatozoa are sufficient to activate the oocyte, the presence of several supernumerary spermatozoa in the cytoplasm of the oocyte is a prerequisite for embryogenesis. ${ }^{52}$

\section{Low sperm numbers}

Later we shall discuss that in animals that produce large numbers of spermatozoa, dilution (externally fertilizing species) or dilution and regulation in the reproductive tract (internally fertilizing species) followed by a bottleneck created by the oocyte extracellular coats reduces the number of spermatozoa at the site of fertilization. In other animals, 
such as some insects and nematode worms, sperm utilization is very efficient. In Drosophila, Leufre and Johnson ${ }^{53}$ discovered a 1:1 ratio between the progeny produced and the number of sperms in the seminal receptacles. In the nematode worm, Caenorhabditis elegans, every spermatozoon fertilizes an oocyte; however, not all oocytes are fertilized because in fact oocytes are produced in excess. ${ }^{54}$ This high efficiency of sperm utilization in insects and nematodes may be an important adaptation as it enables a minimal volume and nutrients for the stored sperm. ${ }^{55}$ Low numbers reduce genetic variability, which may be offset by sperm displacement from second matings. ${ }^{54,55}$

\section{The culprits: sea urchins and mammals \\ Dilution, transport, and chemotaxis External fertilization}

In externally fertilizing animals, such as the sea urchin, it is commonly thought that oocytes and spermatozoa are released into the environment in an uncontrolled haphazard mode with the oocytes being bombarded by hoards of competent spermatozoa. Fertilization starts with the interaction of gametes at the level of their extracellular coats, followed by interaction at the cellular level, leading to sperm entry and ending with the formation of the zygote. In order to progress, each gamete must encounter and respond to a correct sequence of signals from its partner. It is not, as suggested by Rothschild in the 1940 s, a first-order chemical reaction but a fine-tuned, gradual, and controlled encounter of gametes. ${ }^{23}$ Fertilization success in nature depends on the spawning behavior of the organisms, population size, current velocity, oocyte size, sperm swimming capacity, and many other factors. It is true that sea urchins produce $\sim 10,000$ spermatozoa for every oocyte produced, ${ }^{23}$ which incidentally is one-hundredth of the favored concentration used in the laboratory $\left(10^{6} / \mathrm{mL}\right)$; however, data collected from natural spawnings show a low fertilization rate, with fertilization success in free-spawning benthic organisms often $<1 \%{ }^{56}$ Thus, in the environment, sperm-oocyte collisions are rare, and the availability of sperm may affect female reproductive success (see review on sperm limitation). ${ }^{57}$

After spawning, sea urchin sperm motility is activated by exposure to the higher $\mathrm{pH}$ of the sea water, which leads to the activation of $\mathrm{Na}^{+} / \mathrm{H}^{+}$exchanger and a Dynein ATPase. ${ }^{58}$ Lillie was the first to show that in sea urchins sperm behavior is further modulated by factors released from the extracellular coats of the oocyte. ${ }^{59}$ Since then, many sperm-activating peptides in the jelly layer have been identified, for example, speract and resact. ${ }^{60}$ Sperm-activating peptides stimulate sperm motility and respiration by a cascade of intracellular signaling events that involve cyclic nucleotides, $\mathrm{pH}$, and $\mathrm{Ca}^{2+} \cdot{ }^{60-63}$ Since the jelly layer can be removed without impeding fertilization, it has often been considered an accessory rather than an integral part of the oocyte. The jelly is composed of high molecular weight fucose-sulfate-rich glycoconjugates and the $\mathrm{pH}$ in some species is lower (6.3-7.6) than that of the surrounding sea water (7.8-8.2), ${ }^{64}$ which may play a role both in maintaining the metabolic repression of the oocyte and regulating sperm-oocyte interaction. Hagstrom ${ }^{11}$ has shown that even at relatively high sperm:oocyte ratios, $90 \%$ of spermatozoa are unable to penetrate the jelly layer and remain immobilized at various depths within the jelly. Those that pass through must arrive in a physiological condition that both promotes binding and subsequently penetration of the vitelline membrane. The radial organization in situ of the jelly layer is unknown; however, a jelly canal at the animal pole has been identified in sea urchins and suggested to be a preferential sperm entry site, analogous to a micropyle. ${ }^{65-67}$ In amphibian oocytes, the jelly is a fibrillar matrix of high molecular weight glycoproteins, interspersed with globular proteins of lower molecular weight, ${ }^{68}$ and an unusual hypertonic milieu of $70 \mathrm{mM} \mathrm{Na}^{+}, 30 \mathrm{mM} \mathrm{K}, 6 \mathrm{mM} \mathrm{Ca}^{2+}$, and $7 \mathrm{mM} \mathrm{Mg}^{2+} .{ }^{69}$ Leaching these ions, in particular calcium, and the low molecular glycoproteins, in hypotonic medium, leads to a marked yet reversible decrease in fertilizability. Considering that in aurans spermatozoa enter the oocyte in the animal hemisphere. ${ }^{33,70}$ it is probable that the jelly layer differs from antipode to antipode.

Thus, in animals with external fertilization: oocyte ratios are extremely low and need to be enhanced by chemotactic mechanisms even to ensure a minimum of oocytes are fertilized. The outer jelly layer attracts and traps spermatozoa, however, incompetent spermatozoa (whether due to the sperm or the oocyte) are prevented from progressing toward the oocyte.

\section{Internal fertilization}

Mammals produce many more spermatozoa than they do oocytes, with the sperm:oocyte ratio at origin being as high as $10^{9}: 1 .^{71}$ Nonetheless, to ensure fertilization, sperm deposition must be synchronized with ovulation. In some mammals, the spermatozoa are deposited in the vagina (eg, humans), in others, such as mice, they are deposited directly into the uterus. However, in both cases the vast majority of spermatozoa are rapidly eliminated from the tract, ${ }^{71,72}$ with a minority reaching the site of fertilization, the ampulla or 
ampulla-isthmic junction. ${ }^{72}$ The major barrier for sperm ascent in mice is the uterotubal junction, with spermatozoa being progressively released from the lower part of the oviductal isthmus at ovulation. In order to avoid premature aging of the oocyte, sperm ascent and oocyte descent to the ampulla must occur synchronously. The first barrier to sperm ascent in humans is the highly folded mucus-filled cervix, where sperm are retained and released over a period of several days. ${ }^{71-73}$ Contractile activity of the uterine wall aids sperm ascension to the lower isthmus, where they are sequestered until ovulation (see studies by Hunter ${ }^{74,75}$ for domestic animals). Spermatozoa stored in the isthmus in pigs are in close contact with the epithelium; ${ }^{76}$ however, the mechanism by which bound sperm are selectively released is not clear. Release may be regulated by changes in the sperm head plasma membrane and capacitation (see also Gualtieri et $\mathrm{al}^{77}$ ). Finally, migration from the isthmus to the ampullae appears to be due to sperm motility and contractile activity of the oviduct. ${ }^{78}$ So in conclusion, in the mammals, the number of sperm that reach the site of fertilization are regulated by the female tract. There is a dramatic variation across the animal kingdom in sperm shape, sperm size, and the numbers produced to maximize fertilization success. In fruit flies, it was shown that owing to competition for storage and sperm displacement, sperm size is selected for, while in passerine, birds selection is stronger on sperm number. ${ }^{79}$ Recently, examining over 100 mammalian species in a meta-analysis on sperm size and number in relation to body mass, Lupold and Fitzpatrick ${ }^{80}$ came to the conclusion that evolutionary responses favored sperm number rather than sperm size with increasing body size, that is, the bigger the animal the greater the selection pressure on the number of sperm per ejaculate rather than sperm length. Essentially, larger animals such as elephants, produce more sperm per ejaculate (corrected for body mass) than a small mammal such as a mouse. Here, again, we encounter the dilution effect.

In the few in vivo studies where spermatozoa have been counted in situ, 700 spermatozoa were found in sheep ampullae ${ }^{81}$ and five in man, ${ }^{82}$ while in rodents the sperm:oocyte ratios at the site of fertilization were usually unity or below. ${ }^{71,75,83-85}$

In human in vitro fertilization, it is the normal practice to inseminate cumulus intact oocytes with a concentration of at least 100,000 spermatozoa $/ \mathrm{mL} .{ }^{86}$ The oocytes remain in this sperm bath for 18 hours until they are cleaned and transferred to fresh medium for a check on whether they have been fertilized correctly or not. When oocytes were removed from the sperm bath at various times prematurely and cultured in a sperm-free medium, it was found that an initial exposure of
5 minutes was sufficient for normal fertilization to progress. In these cases, approximately ten spermatozoa entered the cumulus complex, with one successfully reaching and fertilizing the oocyte. Those that did not were often blocked at various levels in the cumulus complex. ${ }^{87}$ This study shows that in the mammals, hoards of spermatozoa are not required for normal fertilization and coincides with the concept that in natural in vivo insemination, not more than a handful of spermatozoa approach the oocyte. It is an open debate as to whether or not mammalian spermatozoa respond to chemotactic stimuli, ${ }^{88}$ an odorant receptor gene expressed in the testis may be involved in sperm chemotaxis in humans. ${ }^{89,90}$ Chemical modulation of the zona by oviductal-specific glycoproteins before the oocyte encounters the spermatozoon has been described, which may also be involved in the fine tuning of sperm-oocyte interactions in mammals. ${ }^{91,92}$

In conclusion, few spermatozoa reach the oocyte under natural conditions, of those that do, some are not able to progress through the outer oocyte coating, the cumulus oophorus. A second extracellular coat, the zona pellucida, which impedes sperm progression even further is composed of several glycoproteins that differ between species. ${ }^{93-98}$ The zona pellucida serves to modulate sperm binding and to protect the embryo during early development; however, we know little about its topographical constitution and if indeed sperm entry is piloted to a specific site. Experiments on mammalian oocytes deprived of their outer investments led to the idea that different species had developed different "polyspermy blocking mechanisms" ranging from the plasma membrane, as in the rabbit, ${ }^{81}$ to the zona pellucida as in the sheep and pig, ${ }^{99}$ or a combination of both as in the mouse. ${ }^{99}$ An equally plausible alternative explanation is that the spermatozoa exposed to an incorrect sequence of oocyte signals, due to investment removal, behave differently from one species to the next.

In many animals, including mammals, the extracellular coats may be removed without inhibiting fertilization and these initial gamete interactions may be bypassed by microinjecting the spermatozoon directly into the oocyte. This is often erroneously interpreted as showing the inutility of the extracellular coats and is purely a laboratory artifact. In nature, passage through these coats is a prerequisite for normal fertilization, oocyte activation, and subsequent paternal nuclear decondensation.

Finally, the last barrier for sperm interaction is the plasma membrane and to date there is still little information on its structure. In a preliminary study at the scanning electron microscope, the plasma membrane of the human metaphase II 
oocyte appears to be unpolarized; however, further molecular studies are necessary to determine whether or not spermatozoa may fuse at any site around the plasma membrane. ${ }^{100}$ The plasma membrane in mouse and rat oocytes is polarized with a flat microvillus-free area overlying the metaphase spindle where spermatozoa are not able to fuse. ${ }^{101,102}$

The cortical reaction in mammals appears to follow the same principles as in invertebrates, but is less dramatic and slower. The lateral diffusion of proteins and lipids in the plasma membrane of the mouse oocyte is strongly restricted after fertilization. ${ }^{103}$ The zona pellucida glycoproteins, ZP2 and ZP3, are partially hydrolyzed by a protease released from the cortical granules at fertilization, which causes a hardening of the zona pellucida. ${ }^{94,104,105}$

\section{Back to the laboratory! Activation of the oocyte}

Fertilization is a complex interaction of two complimentary cells, the oocyte and the spermatozoon, where each gamete triggers physiological changes in its partner. In order to proceed through the layers of extracellular coats that surround the oocyte, the spermatozoon encounters a series of consecutive signals that induce changes in its physiology and are a prerequisite for further progression. If one observes sperm-oocyte interaction in echinoderms or mammals with their coats intact, it can be seen that many sperm are halted partially through their voyage. ${ }^{11,28,87}$ Once the spermatozoon has reached the oocyte plasma membrane, and probably following fusion of the two cells, this small cell $(<500,000$ times the volume of the oocyte) triggers the quiescent oocyte into metabolic activity that eventually leads to meiotic resumption and formation of the zygote. The first signs of oocyte activation are changes in the ion permeability of the plasma membrane and the entry and subsequent release of intracellular calcium. While the former maybe localized to the site of sperm entry, the latter starts at the entry site and spreads in an autocatalytic wave to the antipode. Simultaneously, and probably in conjunction, there is a massive reorganization of the cell cortex involving cytoskeletal elements and a cascade of cell cycle kinases. All activation events are propagative and have precise temporal and spatial characteristics that are predetermined and independent of sperm concentration.

In stark contrast to somatic cell biology, oocyte activation that involves thousands of biochemical and physiological pathways simultaneously progressing in a spatial and temporal pattern does not lend itself to traditional molecular biological studies, such as depletion or over expression of any particular component. Activation processes are not specific to gametes, but are biochemical and physiological processes common to all cells, however, with different kinetics.

\section{Inducing polyspermy in the laboratory}

In the echinoderms and mammals, under natural conditions, very few sperm reach the site of fertilization and those that do are often trapped or prevented from progressing through the intracellular coats. The fact remains that in the laboratory, using oocytes depleted of their extracellular coats and unnaturally high sperm densities, often only one sperm enters. Inducing polyspermy in these animals in the laboratory is instrumental in elucidating the mechanism of sperm entry.

During maturation, a series of physiological and structural changes creates a cell unit geared to interact with the fertilizing spermatozoon at a particular moment in time called cytoplasmic maturity. This is often asynchronous with nuclear maturity as first shown by Delage. ${ }^{7}$ If the oocyte is not fertilized, the maturation process continues and the cell ages lead to polyspermy, parthenogenesis, apoptosis, early extrusion of cortical granules, a decrease in M-phase-promoting factor and mitogenactivated protein kinases and changes in histone acetylation.

Sea urchin oocytes may age in the ovary, ${ }^{8}$ or after removal from the ovary; however, in the latter situations the process is considerably accelerated. Aging is associated with a lower rate of oxygen consumption, ${ }^{8}$ alterations to membrane permeability and the cytoskeleton, ${ }^{9}$ and dissolution of the jelly layer and precocious dissolution of the cortical granules. Thus, aged sea urchin oocytes have altered receptivity to spermatozoa, a condition that can be mimicked by treating oocytes with a variety of physical and chemical agents such as heat shock and nicotine, ${ }^{106,107}$ and drugs that affect actin. ${ }^{108}$ The latter authors have also cast doubt on the existence of a slow block to polyspermy in sea urchin oocytes, since they demonstrated that multiple sperm entry may occur in the presence of a fertilization membrane and no sperm entry when the fertilization membrane was prevented from elevating. Polyspermy is also common in aged mammalian oocytes, both in vivo and in vitro. ${ }^{109}$

\section{Privileged sperm entry}

If we observe fertilization in the sea urchin oocyte, with moderate sperm densities, we see that many sperm attach to the oocyte surface gyrating around their attachment sites. One becomes motionless with the tail stiffening perpendicular to the oocyte surface (Figure 1). This is the successful spermatozoon that induces the step depolarization ${ }^{25}$ and simultaneously the cortical flash, which is the global instantaneous release of cortical calcium that precedes the calcium wave by 10 seconds (the latent period). ${ }^{110}$ The successful 


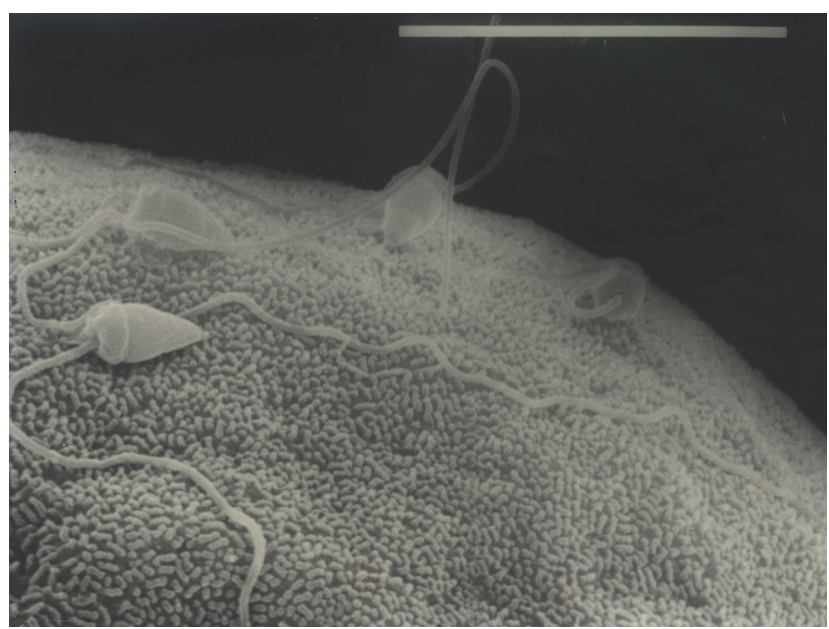

Figure I Spermatozoa on the surface of a sea urchin oocyte.

Note: Are they attached to sites which permit entry?

spermatozoon, by virtue of its competence, or because it is attached to a predetermined site, is different to its counterparts. There is no evidence that supernumerary spermatozoa are physiologically equivalent, nor if they are attached to parts of the oocyte surface that would permit entry (Figure 1). Consequently, there is no reason to believe that activation events would prevent their further progression.

The length and density of microvilli, location of cortical granules, ${ }^{21,27,111}$ and the priming of the intracellular $\mathrm{Ca}^{2+}$ release mechanism ${ }^{112}$ are events in oocytes that are tightly controlled by the actin cortical cytoskeleton. ${ }^{113}$ In the 1970s, it was already suggested that G-actin, sequestered on the membrane, polymerizes during the first few seconds of sperm-oocyte interaction. ${ }^{114,115}$ In the starfish oocyte, the acrosome reaction can be seen to be induced at the outer layer of the jelly and a long tubule then grows from the tip of the spermatozoon to perforate the jelly and the vitelline coat to fuse with the oocyte plasma membrane. ${ }^{116}$ The successful spermatozoon needs to encounter a series of consecutive signals that induces changes in its physiology and are a prerequisite for progression before triggering a localized subcortical polymerization of actin, beneath the fertilization cone, which is then involved in the movement of the spermatozoon into the oocyte. ${ }^{113,117}$ At high sperm densities, several sperm may undergo the acrosome reaction, contacting the oocyte plasma membrane, but these unsuccessful spermatozoa induce transient localized activation events that abort. Only one, the successful spermatozoon, locates a site that induces a complete fertilization response that propagates globally and leads to sperm entry. This successful sperm anchor site is regulated by the underlying actin cytoskeleton and, in any case, must be predetermined. ${ }^{117}$

\section{Disclosure}

The authors report no conflicts of interest in this work.

\section{References}

1. Just EE. The fertilization reaction in eggs of paracentrotus and echinus. Biol Bull. 1929;36:326-331.

2. Just EE. The Biology of the Cell Surface. Philadelphia: Blackiston's Son \&Co., Inc; 1939

3. Ernst SG. A century of sea urchin development. Am Zool. 1997;37:250-259.

4. Monroy A. The Chemistry and Physiology of Fertilization. New York: Holt, Rinehart and Winston; 1963.

5. Rothschild L. Polyspermy. Q Rev Biol. 1954;29:332-342.

6. Jaffe LA. Fast block to polyspermy in sea urchin eggs is electrically mediated. Nature. 1976;261:68-71.

7. Delage Y. Etudes experimentales chez les Echinodermes [Experimental studies in echinoderms]. Arch Zool Exp et Gen. 1901;9:285-326. French.

8. Borei H. Respiration of oocytes, unfertilized eggs and fertilized eggs from Psammechinus and Asterias. Biol Bull. 1948;95:124-150.

9. Runnstrom J, Monne L. On Some Properties of the Surface Layers of Immature and Mature Sea Urchin Eggs, Especially the Changes accompanying Nuclear and Cytoplasmic Maturation. Stockholm: Almqvist \& Wiksell; 1945.

10. Ghazarian H, Coyle Thomson C, Dalrymple W, et al. Exogenous hyaline and sea urchin gastrulation. Part IV: a direct adhesion assay - progress in identifying hyalins active sites. Zygote. 2010;18:17-26.

11. Hagstrom B. Further experiments on jelly-free sea urchin eggs. Exp Cell Res. 1959;17:256-261.

12. Lonning S. Studies of the ultrastructure of sea urchin eggs and the changes induced at insemination. Sarsia. 1967;30:31-48.

13. Carroll EJ, Epel D. Isolation and biological activity of the proteases released by sea urchin eggs following fertilization. Dev Biol. 1975;44:22-32.

14. Chandler DE, Heuser J. The vitelline layer of the sea urchin egg and its modification during fertilization. J Cell Biol. 1980;84:618-632.

15. Kidd P. The jelly and vitelline coats of the sea urchin egg: new ultrastructure features. J Ultrastr Res. 1978;64:204-215.

16. Vacquier VD, Tegner MJ, Epel D. Protease activity establishes the block against polyspermy in sea urchin eggs. Nature. 1973;240:352-353.

17. Rothschild L, Swann MM. The fertilization reaction in the sea urchin egg. A propagated response to sperm attachment. $J$ Exp Biol. 1948;26:164-176.

18. Rothschild L, Swann MM. The fertilization reaction in the sea urchin. The probability of a successful sperm-egg collision. J Exp Biol. 1951;28:403-416.

19. Rothschild L, Swann MM. The fertilization reaction in the sea urchin. The block to polyspermy. J Exp Biol. 1952;29:469-483.

20. Shen SS, Steinhardt RA. Time and voltage windows for reversing the electrical block to fertilization. Proc Natl Acad Sci. 1984;81:1436-1439.

21. Hinkley RE, Wright BD, Lynn JW. Rapid visualization of sperm-egg fusion using the DNA specific fluorochrome Hoechst 33342. Dev Biol. 1986;118:148-154.

22. Lynn JW, Mculloh DH, Chambers EL. Voltage clamp studies of fertilization in sea urchin eggs. Current patterns in relation to sperm entry, non-entry and activation. Dev Biol. 1988;128:305-323.

23. Dale B, Defelice LJ, Polyspermy prevention: facts and artifacts. JAssist Reprod Genet. 2011;28:199-207.

24. Dale B, DeSantis A. Maturation and fertilization of the sea urchin oocyte: an electrophysiological study. Develop Biol. 1981;85:474-484.

25. Dale B, De Felice LJ, Taglietti V. Membrane noise and conductance increase during single spermatozoon-egg interactions. Nature. 1978;275:217-219.

26. Dale B, De Santis A. The effect of cytochalasin b and d on the fertilization of sea urchins. Dev Biol. 1981;83:232-237. 
27. Dale B, Santella L. Sperm-oocyte interaction in the sea urchin. J Cell Sci. 1985;74:153-167.

28. Dale B. Sperm receptivity in sea urchin oocytes and eggs. J Exp Biol. 1985;118:85-97.

29. Longo FJ, Lynn JW, McCulloch D, et al. Correlative ultrastructural and electrophysiological studies of sperm egg interactions of the sea urchin. Lytechinusvariegatus Dev Biol. 1986;118:155-166.

30. Dale, B, Monroy A. How is polyspermy prevented? Gamete Res. 1981;4:151-169.

31. Dale B. Fertilization in Animals. London: Edward Arnold; 1983.

32. Yanagimachi R, Cherr G, Matsubara T, et al. Sperm attractant in the micropyle region of fish and insect eggs. Biol Reprod. 2013;88:1-11.

33. Campanella C. The site of spermatozoon entrance in the unfertilized egg of Discoglossus pictus (Anura): an electron microscopy study. Biol Reprod. 1975;12:439-447.

34. Dale B, Wilding M, Coppola GF, Tosti E. How do spermatozoa activate oocytes. Reprod Biomed Online. 2010;21:1-3.

35. Busa WB, Nuccitelli R. An elevated free cytosolic $\mathrm{Ca}^{2+}$ wave follows fertilization in eggs of the frog Xenopus laevis. $J$ Cell Biol. 1985;100:1325-1329.

36. Yamashita M. A fine structural study of the fertilization process of the jellyfish Cladonema uchidai. Dev Growth Differ. 1988;30:81-91.

37. Wilding M, Marino M, Monfrecola V. Dale B. Meiosis associated calcium waves in ascidian oocytes are correlated with the position of the male centrosome. Zygote. 2000;8:285-293.

38. Stricker S. Repetitive calcium waves induced by fertilization in the nemertean worm Cerebratulus lacteus. Dev Biol. 1996;176:243-263.

39. Ridgeway EB, Gilkey JC, Jaffe LF. Free calcium increases explosively in activating medaka eggs. Proc Natl Acad Sci. 1997;74:623-627.

40. Gilkey JC, Jaffe LF, Ridgeway EB, et al. A free calcium wave traverses the activating egg of the medaka Oryzias latipes. J Cell Biol. 1978; 76:448-466.

41. Yoshimoto Y, Iwamatsu T, Hirano K, Hiramoto Y. The wave pattern of free calcium release upon fertilization in medaka and sand dollar eggs. Dev Growth Differ. 1986;28:583-596.

42. Miyazaki S, Hashimoto N, Yoshimoto Y. Temporal and spatial dynamics of the periodic increase in intracellular free calcium at fertilization of golden hamster eggs. Dev Biol. 1986;118:259-267.

43. Deguchi R, Shirakawa H, Oda S, Mohri T, Miyazaki S. Spatiotemporal analysis of $\mathrm{Ca}^{2+}$ waves in relation to the sperm entry site and animal vegetal axis during $\mathrm{Ca}^{2+}$ oscillations in fertilized mouse eggs. Dev Biol. 2000;218:299-313.

44. Swann K, Ozil, J. Dynamics of the calcium signal that triggers mammalian egg activation. Int Rev Cytol. 1994;152:183-222.

45. Whitaker M, Swann K. Lighting the fuse at fertilization. Development. 1993;117:112-120.

46. Snook R, Hosken D, Karr T. The biology and evolution of polyspermy: insights from cellular and functional studies of sperm and centrosomal behaviour in the fertilized egg. Reproduction. 2011;142:779-792.

47. Fankhauser G. Analyse der physiologischen polyspermie ded Triton Eies auf grund von schnuerungsexperimenten. Arch Entw Mech. 1925;105:501-580. German.

48. Fankhauser G. Cytological studies on egg fragments of the salamander Triton. The history of supernumerary sperm nuclei in normal fertilization and cleavage of fragments containing the egg nucleus. J Exp Zool. 1932;62:185-235.

49. Fankhauser $\mathrm{G}$. The organization of the amphibian egg during fertilization and cleavage. Ann NY Acad Sci. 1948;49:684-707.

50. Harper EH. The fertilization and early development of the pigeon's egg. Am J Anat. 1904;3:349-386.

51. Bakst MR, Wishart, G, Brillard, JP. Oviductal sperm selection transport and storage in poultry. Poult Sci Rev. 1994;5:117-143.

52. Hemmings N, Birkhead T. Polyspermy in birds: sperm numbers and embryo survival. Proc Biol Sci. 2015;282:20151682.

53. Leufre G, Johnson U. Sperm transfer, storage displacement and utilization in Drosophila melanogaster. Genetics. 1962;47:1719-1736.
54. Ward S, Carroll J. Fertilization and sperm competition in the nematode Caenorhabditis elegans. Dev Biol. 1979;73:304-321.

55. Parker G. Sperm competition and its evolutionary consequences in the insects. Biol Rev. 1970;45:525-567.

56. Levitan D. The importance of sperm limitation to the evolution of egg size in marine invertebrates. Am Nat. 1993;141:517-536.

57. Levitan D, Peterson C. Sperm limitation in the sea. Trends Ecol Evol. 1995;10:228-231.

58. Darszon A, Labarca P, Nishigaki T, Espinosa F. Ion channels in sperm physiology. Physiol Rev. 1999;79:481-510.

59. Lillie F. Studies on fertilization V. The behavior of the spermatozoa of Nereis and Arbacia with special reference to egg extracts. J Exp Biol. 1913;14:515-574.

60. Suzuki N, Nomura K, Ohtake H, Isaka S. Purification and the primary structure of sperm activating peptides from the jelly coat of sea urchin eggs. Biochem Biophys Res Commun. 1981;99:1238-1244.

61. Suzuki N. Structure function and biosynthesis of sperm activating peptides and fucose sulphate glycoconjugate in the extracellular coat of sea urchin eggs. Zool Sci. 1995;12:13-27.

62. Suzuki N, Yoshino Y. The relationship between amino acid sequences of sperm-activating peptides from the jelly coat of sea urchin eggs. Comp Biochem Physiol. 1992;102:679-690.

63. Cook SP, Brokaw CJ, Muller CH, Babcock DF. Sperm chemotaxis: egg peptides control cytosolic calcium to regulate flagellar responses. Dev Biol. 1994;165:10-19.

64. Ciccarelli C, Russo P, De Santis A, Dale B. pH in the jelly layer of starfish oocytes. Dev Growth Differ. 1987;29:257-261.

65. Boveri T. Die polaritat von Ovocyte ei und Larvae des Stronglocentrotus lividus [The polarity of Ovocyte egg and larvae of Stronglocentrotus lividus]. Zool Jb Morph. 1901;14:630-651.

66. Runnstrom J. The mechanism of fertilization in metazoa. Adv Enzymol. 1949;9:241-327. German.

67. Runnstrom J. The mechanism of protection of eggs against polyspermy. Experiments on the sea urchin Paracentrotus lividus. Ark Zool. 1961;13:565-571.

68. Bonnell B, Chandler D. Egg jelly layers of Xenopus laevis are unique in ultrastructure and sugar distribution. Mol Reprod Dev. 1966;44: 212-220.

69. Medina M, Crespo C, Ramos I, et al. Role of cations as components of jelly coat in Bufo arenarum fertilization. Zygote. 2010;18:69-80.

70. Grey R, Bastiani MJ, Webb DJ, Schertel ER. An electrical block is required to prevent polyspermy in eggs fertilized by natural mating of Xenopus laevis. Dev Biol. 1982;89:475-484.

71. Yanagimachi R. Mammalian fertilization. In: Knobil E, Neill JD, editors. The Physiology of Reproduction. 2nd ed. New York: Raven; 1994.

72. Suarez S. Gamete transport. In: Hardy DM, editor. Fertilization. New York: Academic; 2002.

73. Hanson BW, Overstreet JW. The interaction of human spermatozoa with cervical mucus in vivo. Am J Obstet Gynaecol. 1981;140:173-178.

74. Hunter RHF. Physiology and Technology of Reproduction in Female Domestic Animals. New York: Academic; 1980.

75. Hunter RHF. Ovarian control of very low sperm:egg ratios of the commencement of mammalian fertilisation to avoid polyspermy. Molec Reprod Dev. 1996;44:417-422.

76. Flechon JE, Hunter RHF. Distribution of spermatozoa in the utero-tubal junction and isthmus of pigs and there relationship with the luminal epithelium after mating. Tissue Cell. 1981;13:127-139.

77. Gualtieri R, Mollo V, Barbato V, Talevi R. Ability of sulphate glycoconjugates and disulfide-reductants to release bovine epididymal sperm bound to the oviductal epithelium in vitro. Theriogenology. 2010;73:1037-1043.

78. Hunter RHF. The Fallopian Tubes. Berlin: Springer Verlag; 1988.

79. Imler S, Pitnick S, Parker G, et al. Resolving variation in the reproductive tradeoff between sperm size and number. Proc Natl Acad Sci USA. 2011;108:5325-5330.

80. Lupold SA, Fitzpatrick J. Sperm number trumps sperm size in mammalian ejaculate evolution. Proc Biol Sci. 2015;282:20152122. 
81. Braden AWH, Austin CR. The number of sperms about the eggs in mammals and its significance for normal fertilization. Aust J Biol Sci. 1954;7:543-551.

82. Doak RL, Hall A, Dale HE. Longevity of spermatozoa in the reproductive tract of the bitch. J Reprod Fertil. 1967;13:51-58.

83. Stefanini M, Oura I, Zamboni I. Ultrastructure of fertilization in the mouse: penetration of sperm into ovum. J Submicro Cytol. 1969;1:1-23.

84. Bedford JM. The rate of sperm passage into the cervix after coitus in the rabbit. J Reprod Fertil. 1971;25:211218.

85. Bedford J, Phillips D, Mover-Lev H. Novel sperm crypts and behavior of gametes in the fallopian tube of the white toothed shrew Crocidura russula Monacha. J Exp Zool. 1977;277:262-273.

86. Elder K, Dale B. In vitro Fertilization. 3rd ed. Cambridge, UK: Cambridge University Press; 2011.

87. Gianaroli L, Magli C, Ferraretti A, et al. Reducing the time of spermoocyte interaction in human IVF improves the implantation rate. Hum Reprod. 1996;11:166-171.

88. Williams M, Hill CJ, Scudamore I, et al. Sperm numbers and distribution within the human fallopian tube around ovulation. Hum Reprod. 1993;8:2019-2126.

89. Vosshall LB. Olfaction: attracting both sperm and the nose. Curr Biol. 2004;14:918-920.

90. Spehr M, Gisselmann G, Poplawski A, et al. Identification of a testicular odorant receptor mediating human sperm chemotaxis. Science. 2003;299:2054-2058.

91. Coy P, Avilès M. What controls polyspermy in mammals: the oviduct or the oocyte? Biol Revs. 2010;85:593-605.

92. Coy P, Canovas S, Mondejar I, et al. Oviduct specific glycoprotein and heparin modulate sperm zona pellucida interaction during fertilization and contribute to the control of polyspermy. Proc Natl Acad Sci USA. 2008;105:15809-15814.

93. Baibakov B, Gauthier L, Talbot P, Rankin, TL, Dean J. Sperm binding to the zona pellucida is not sufficient to induce acrosome exocytosis. Development. 2007;134:933-943.

94. Gahlay G, Gauthier L, Baibakov B, Epifano O, Dean J. Gamete recognition in mice depends on the cleavage status of an egg's zona pellucida protein. Science. 2010;329:216-219.

95. Goudet G, Mugnier S, Callebaut I, Monget P. Phylogenetic analysis and identification of pseudogenes reveal a progressive loss of zona pellucida genes during evolution of vertebrates. Biol Reprod. 2008;78: 796-806.

96. Izquierdo-Rico MJ, Jimenez-Movilla M, LLop E, et al. Hamster zona pellucida is formed by four glycoproteins ZP1, ZP2, ZP3 and ZP4. J Proteome Res. 2009;8:926-941.

97. Plaza S, Chanut-Delalande H, Fernandes I, Wassarman P, Payre F. From A to $\mathrm{Z}$ : apical structures and zona pellucida-domain proteins. Trends Cell Biol. 2010;20:524-532.
98. Wassarman P, Litscher E. Eggs ZP3 structure speaks volumes. Cell. 2010;143:337-338.

99. Austin CR. Fertilization. Englewood Cliffs, NJ: Prentice-Hall; 1965.

100. Santella L, Alikani M, Talansky B, Cohen J, Dale B. Is the human oocyte plasma membrane polarized. Hum Reprod. 1992;7:999-1003.

101. Shalgi R, Philips D. Mechanisms of sperm entry in cycling hamster. J Ultrastructural Res. 1980;71:154-161.

102. Philips D, Shalgi R. Sperm penetration into rat ova fertilized in vivo. J Exp Biol. 1982;221:373-378.

103. Johnson M, Edidin M. Lateral diffusion in plasma membrane of mouse eggs is restricted after fertilization. Nature. 1978;272:448-450.

104. Ducibella T. The cortical reaction and development of activation competence in mammalian oocytes. Hum Reprod Update. 1996;2:29-42.

105. Moller C, Wassarman P. Characteristics of a proteinase that cleaves zona pellucida glycoprotein ZP2 following activation of mouse eggs. Dev Biol. 1989;132:103-112.

106. Rothschild L. The fertilization reaction in the sea urchin: the induction of polyspermy by nicotine. J Exp Biol. 1953;30:57-67.

107. Dale B, DeSantis A, Hagstrom B. The effect of nicotine on sperm-egg interaction in the sea urchin: polyspermy and electrical events. Gamete Res. 1982;5:125-135.

108. Chun J, Limatola N, Vasilev F, Santella L. Early events of fertilization in sea urchin eggs are sensitive to actin-binding organic molecules. Biochem Biophys Res Commun. 2014;450:1166-1174.

109. Hunter RHF. The effects of delayed insemination on fertilization and early cleavage in the pig. J Reprod Fertil. 1967;13:133-147.

110. Santella L, Limatola N, Chun J. Calcium and actin in the saga of awakening oocytes. Biochem Biophys Res Commun. 2015;460:104-113.

111. Runnstrom J. Sperm induced protrusions in sea urchin oocytes: a study of phase separation and mixing in living cytoplasm. Dev Biol. 1963;7:38-50.

112. Whitaker M. Calcium at fertilization and in early development. Physiol Rev. 2006;86:25-88.

113. Santella L, Vasilev F, Chung JT. Fertilization in echinoderms. Biochem Biophys Res Commun. 2012;425:588-594.

114. Spudich A, Spudich JA. Actin in triton treated cortical preparations of unfertilized and fertilized sea urchin eggs. J Cell Biol. 1979;82: 212-226.

115. Wang YL, Taylor DL. Distribution of fluorescent labeled actin in living sea urchin eggs during early development. J Cell Biol. 1979;82: 672-679.

116. Dale B, Dan-Sohkawa M, De Santis A, Hoshi M. Fertilization of the starfish Astropecten aranciacus. Exp Cell Res. 1981;132:505-510.

117. Puppo A, Chun JT, Gragnaniello G, Garante E, Santella L. Alteration of the cortical actin cytoskeleton deregulates $\mathrm{Ca}^{2+}$ signalling monospermic fertilization and sperm entry. PLOS ONE. 2008;3(10): e3588.
Research and Reports in Biology

\section{Publish your work in this journal}

Research and Reports in Biology is an international, peer-reviewed, open access journal publishing original research, reports, editorials, reviews and commentaries on all areas of biology including animal biology, biochemical biology, cell biology, ecological studies, evolutionary biology, molecular biology, plant science and botany. The

\section{Dovepress}

manuscript management system is completely online and includes a very quick and fair peer-review system. Visit http://www.dovepress. com/testimonials.php to read real quotes from published authors. 